\title{
Формы человеческого капитала региона и особенности выбора индикаторов их оценки в условиях цифровой трансформации
}

\author{
Стрябкова Е.А., Вейс Е.В. \\ Белгородский государственный национальный исследовательский университет, \\ Россия, 308015, г. Белгород, ул. Победы, 85 \\ Тамбовский государственный университет имени Г.Р. Державина, \\ 392036, Россия, г. Тамбов, ул. Интернациональная, 33 \\ E-mail: Stryabkova@bsu.edu.ru, bupsi980-90@mail.ru
}

\begin{abstract}
Аннотация
Рассматриваются основные формы человеческого капитала региона, основные индикаторы его оценки в условиях цифровой экономики. Цифровая экономика оказывает влияние на основные характеристики человеческого капитала региона, меняя структуру основных элементов, составляющих основу человеческого капитала, расширяя формы человеческого капитала региона. Определено, что к основным формам человеческого капитала в условиях цифровой трансформации относятся: физическая, интеллектуальная, организационная, социальная и сетевая форма. Выявлены особенности анализа человеческого капитала региона в аспекте их проявления; предложена структура индикаторов для оценки основных форм человеческого капитала региона с позиции цифровизации. Построена система агрегированных индикаторов человеческого капитала на основании видовой диверсификации человеческого капитала - форм, подверженных изменениям, возникших в процессе влияния цифровых трансформаций на общество, а также их основных обособленных элементов, уровней и стадий воспроизводства, характеризующих данное видовое разнообразие с различных сторон рассмотрения.
\end{abstract}

Ключевые слова: человеческий капитал, регион, форма человеческого капитала, индикатор оценки, цифровая экономика.

Благодарности: исследование выполнено в рамках государственного задания НИУ «БелГУ» FZWG2020-0016 (0624-2020-0016), тема проекта «Фундаментальные основы глобальной территориальноотраслевой специализации в условиях цифровизации и конвергенции технологий».

Для цитирования: Стрябкова Е.А., Вейс Е.В. 2020. Формы человеческого капитала региона и особенности выбора индикаторов их оценки в условиях цифровой трансформации. Экономика. Информатика. 47 (4): 700-709. DOI 10.18413/2687-0932-2020-47-4-700-709.

\section{Forms of human capital of the region and features of the choice of indicators of their evaluation in the conditions of digital transformation}

\author{
Stryabkova E.A., Veiss E.V. \\ Belgorod National Research University, 85 Pobedy St, Belgorod, 308015, Russia \\ Tambov State University named after G. R. Derzhavin, 33 International St, Tambov, 392036, Russia \\ E-mail: Stryabkova@bsu.edu.ru ,bupsi980-90@mail.ru
}

\begin{abstract}
The main forms of human capital in the region, the main indicators of its assessment in the digital economy are considered. The digital economy affects the main characteristics of the region's human capital, changing the structure of the main elements that make up the basis of human capital, expanding the forms of human capital in the region. It is determined that the main forms of human capital in the conditions of digital transformation include physical, intellectual, organizational, social and network forms. The features of the analysis of the region's human capital in the aspect of their manifestation are revealed; the structure of indicators for evaluating the main forms of the region's human capital from the perspective of digitalization is
\end{abstract}


proposed. Built a system of aggregated indicators of human capital based on the species diversification of human capital - form, subject to changes arising during the impact of digital transformation on society, and their major separate elements, levels and stages of reproduction that characterizes the species diversity from different angles of consideration.

Keywords: human capital, region, form of human capital, evaluation indicator, digital economy.

Acknowledgements: the research was carried out within the framework of the state assignment of NRU BelSU FZWG-2020-0016 (0624-2020-0016), the topic of the project "Fundamental foundations of global territorial and industry specialization in the context of digitalization and technology convergence".

For citation: Stryabkova E.A., Veiss E.V. 2020. Forms of human capital of the region and features of the choice of indicators of their evaluation in the conditions of digital transformation. Economics. Information technologies. 47 (4): 700-709 (in Russian). DOI 10.18413/2687-0932-2020-47-4-700-709.

\section{Введение}

Распространение цифровой экономики приводит к запуску трансформационных процессов во всех сферах экономики. Видоизменяются формы производства, трансформируются формы потребления, предприятия вступают в новый этап индустриализации, связанной с развитием цифровых технологий. Данная трансформация приводит к изменениям, связанным с формированием человеческого капитала в регионах. На формирование новых навыков, компетенций человеческого капитала оказывает влияние так называемая цифровая среда, формирующая новую форму составляющей человеческого капитала - сетевую форму. Сетевая форма человеческого капитала, в интегральном единстве с остальными формами человеческого капитала, способствует формированию новых навыков, в том числе и цифровых, и переводит человеческий капитал региона на новый этап развития. В связи с данным процессом растет необходимость определения основных форм человеческого капитала региона и выбор грамотной структуры индикаторов оценки каждой формы.

В процессе данного исследования для решения поставленной задачи были использованы общенаучные диалектические и количественные методы исследования, в том числе анализ, синтез, системно-холистический подход, принцип рассмотрения явлений от общего к особенному и частному.

\section{Основные результаты исследования}

Развитие цифровой экономики способствует формированию в регионе человеческого капитала, обладающего новыми качественными характеристиками. В условиях цифровой экономики человеческий капитал эволюционирует, меняет свою содержательную характеристику, так как цифровые преобразования экономики предполагают наличие у человека определенного рода свойств, пользующихся спросом в условиях инновационной экономики. Цифровые трансформации экономики и современного общества выносят на передний план человека, обладающего большим объемом информации и знаний, интеллектуалоемкие производства вытесняют материальные, развиваясь быстрыми темпами и являясь перспективной и высокодоходной отраслью экономической деятельности. По нашему мнению, в современных условиях человеческий капитал представляет собой интегральное единство основных количественных и качественных параметров, которые формируются за счет инвестирования средств в основные его формы, которые являются источником будущих доходов, так как именно форма, через выражение организации, функционирования и развития, определяет внутреннюю организацию содержания категории «человеческий капитал региона». Образование данных форм требует вложения определенного объема инвестиций. Мы считаем, что к основным формам регионального человеческого капитала в условиях цифровой трансформации относятся: 
региона); региона);

- интеллектуальная форма (характеризует воспроизводственный потенциал населения

- физическая форма (характеризует воспроизводственный потенциал населения региона);

- организационная форма (характеризует уровень трудовой деятельности населения

- социальная форма (совокупность основных характеристик, характеризующих эффективность развития и доходности человеческого капитала);

- сетевая форма (характеризует накопленные знания, навыки и способности человека, приобретенные за счет применения нейросетевых инструментов (интернет-технологий)).

На рисунке 1 представлена схема формирования (основных форм) человеческого капитала региона в условиях цифровой трансформации.

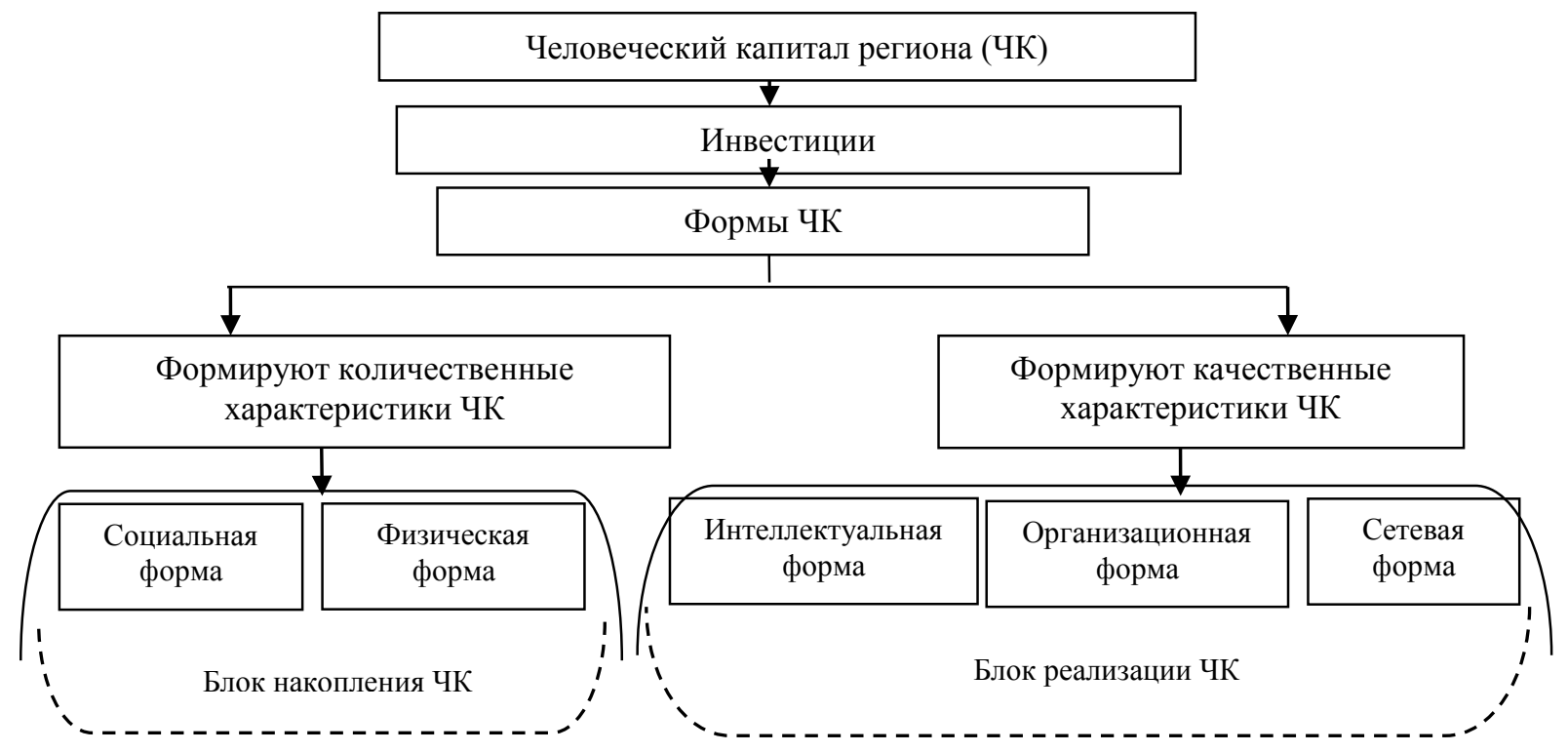

Рис. 1. Основные формы, составляющие понятие «человеческий капитал» региона

Fig. 1. The main forms that make up the concept «Human capital» of the region

Чтобы оценить эффективность формирования человеческого капитала региона, необходимо брать во внимание определенные группы индикаторов, которые в совокупности будут измерять его количество и качество. Данные индикаторы должны охватывать все активы человеческого капитала, а также учитывать его региональные особенности, связанные с его формированием и использованием в условиях цифровой трансформации.

Построение системы индикаторов способствует упрощению анализа человеческого капитала региона за счет формализации и стандартизации исходных данных в разрезе его элементов, уровней, видов и стадий воспроизводства применительно к выявленным формам.

Следовательно, можно выделить четыре направления в рамках систематизации методов построения индикаторов форм человеческого капитала (рис. 2).

Рассмотрим основные индикаторы человеческого капитала с точки зрения дифференцированных апробаций с позиции цифровизации.

В зависимости от стадии воспроизводства человеческого капитала - периодизация рассмотрения структурных элементов человеческого капитала оказывает существенное влияние на их качественную характеристику, выражающуюся в уровне квалификации, образованности и цифровой грамотности населения региона. Особенностью анализа человеческого капитала, в разрезе стадий воспроизводства, является дифференциация характеристик с точки зрения двух подходов. Первый подход - оценка уровня инвестиций в человеческий капитал, посредством 
которого происходит его формирование (затратный метод анализа) [Кирьянов Д.А., Сухарева Т.Н., 2011; Мызин А.Л., Гурбан И. А., 2011]. Второй - оценка доходности элементов человеческого капитала (доходный подход), являющихся базой, а также приобретенных за счет дальнейших инвестиционных вложений. Это объясняется тем, что со временем врожденных персональных навыков становится недостаточно, возникает потребность в получении образования, в ходе дальнейшей деятельности также возникает необходимость в получении дополнительных навыков, повышении квалификации. Необходимость учета инвестиционных вложений в человеческий капитал рассматривается в трудах как зарубежных, так и отечественных ученых [Schulz T.W.,1971; Макконелл В.И., Брю С.Л., 1992; Кедрик Дж,1978; Добрынин А.И., Дятлов С.А., Цыренова Е.Д.,1999], что также подтверждает актуальность данного рода анализа.

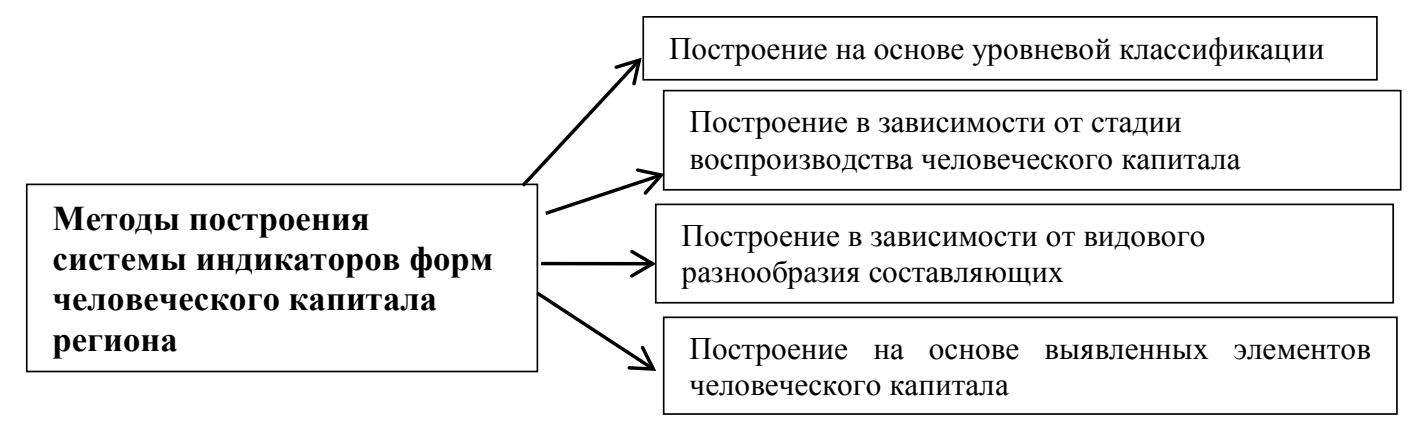

Рис. 2. Систематизация методов построения индикаторов форм человеческого капитала региона

Fig. 2. Systematization of methods for constructing indicators of human regional capital forms

В зависимости от решения о структуре и объемах инвестирования, произведенного в ходе формирования человеческого капитала, определяется уровень реальных и будущих доходов владельца: морального удовлетворения результатом деятельности, финансовых доходов владельца капитала. Данный этап является завершающим элементом модели, позволяющим сделать выводы о продуктивности принятых в ходе формирования капитала решений. Анализ результативности инвестиционных вложений формирует доходный подход к оценке человеческого капитала, ориентированный на использование капитала [Васильева Е., 2010]. Данный метод имеет ряд недостатков, среди которых: низкая вероятность достоверности прогнозов; дифференциация уровня доходов в территориальном и отраслевом аспекте; отсутствие четко выраженных показателей доходности человеческого капитала, отличных от других факторов производства; отсутствие учета нематериальных выгод, связанных с использование человеческого капитала [Соболева И.В., 2009].

В настоящее время наиболее востребованным является представительный подход, основанный на рассмотрении капитала с точки зрения соответствующих ему индикаторов. Представительный подход, в зависимости от представлений авторов об основе оценки, можно дифференцировать на анализ, который определяет индекс, характеризующий развитие человеческого потенциала (ИРЧП) как основы, определяющей уровень человеческого капитала региона [Казмалова О.Н., 2012; Подберезкин А.И., Гебеков М.П., 2011; Руденко Д.Ю., 2012; Спиридонова Е.М., 2010].

Индекс развития человеческого потенциала впервые был опубликован в Докладе о развитии человека в 1990 году - индекс является агрегатным показателем прогресса, измеряющим уровень человеческого капитала в трех направлениях: уровень здоровья, образования и дохода. Расчет ИРЧП основывается на соотношении агрегированных показателей, среди которых: уровень валового внутреннего продукта на душу населения (в 2010 г. был заменен на валовый национальный доход на душу населения [Доклад о развитии человека, 2010]); средняя продолжительность обучения (заменена на уровень грамотности); охват детей школьным образованием (ожидаемая продолжительность обучения) и т. д. С точки зрения анализа уровня человеческого капитала региона - наиболее актуальным является 
применение сводного индекса по индивидуальным методикам [Лосева О.В., 2010; Мызин А.Л., Гурбан И.А., 2011; Шафран А.М., 2011]. В рамках данного подхода авторы предлагают свои методики расчета индекса в зависимости от самостоятельно разработанной структуры человеческого капитала (видового состава капитала, его элементов), а также системы индикаторов, определяющих его уровень.

Мы считаем, что построение системы агрегированных индикаторов человеческого капитала осуществляется на основании видовой диверсификации человеческого капитала форм, подверженных изменениям, возникших в процессе влияния цифровых трансформаций на общество, а также их основных обособленных элементов, уровней и стадий воспроизводства, характеризующих данное видовое разнообразие с различных сторон рассмотрения. Можно выделить следующие критерии построения системы индикаторов в целях анализа форм человеческого капитала с позиции цифровизации: отсутствие перегруженности элементов системы количеством используемых индикаторов в целях упрощения анализа и сбора необходимой информации; актуальность и правдивость данных, представленных для изучения; значение показателей может определяться на основании федеральных и региональных статистических данных; отбор показателей должен осуществляться по степени их наибольшей важности для направления, а также наибольшей информативности; использование только относительных показателей в целях снижения уровня искажения полученных данных; отсутствие индикаторов, являющихся взаимодополняемыми и взаимозаменяемыми.

Резюмируя вышеизложенное, принимая во внимание основные формы человеческого капитала региона, охарактеризуем структуру индикаторов оценки форм человеческого капитала региона.

Оценка физического человеческого капитала, с учетом возможности выявления статистических данных для индикации, позволяет сформировать представление о состоянии и перспективах развития базиса человеческого капитала на мезоуровне.

Интеллектуальная форма человеческого капитала характеризует когнитивные составляющие человеческого капитала, уровень знаний. Особенностями анализа основных компонентов интеллектуальной формы, как физической, является сложность оценки составляющих, в большинстве своем не имеющих натурально-вещественной формы навыков, умений, креативности и т. д.

Организационная форма человеческого капитала характеризует уровень трудовой активности населения региона - уровень занятости и качество трудовых ресурсов, особенности развития предпринимательства в цифровых реалиях современной экономики, а также влияние цифровых преобразований на организацию производственного процесса.

Социальная форма человеческого капитала представляет собой совокупность основных характеристик, характеризующих эффективность развития и доходности человеческого капитала. Основной целью цифровых трансформаций общества является ревалоризация качества жизни населения. Следовательно, оценка тесситуры показателей, характеризующих данное направление развития, позволит сформировать представление о готовности человеческого капитала к обмену с высокими технологиями. Также это позволит выявить уровень влияния цифровых трансформаций на обыденное состояние домохозяйств.

Сетевая форма человеческого капитала характеризует уровень использования населением региона потенциала новых информационных технологий, а также стимулирующий к приобретению и реализации новых трудовых компетенций. При помощи оценки данной формы человеческого капитала можно оценить уровень цифровой грамотности населения, обеспеченности населения цифровыми средствами получения и обработки информации, средствами связи, и доступности Интернет-обслуживания.

Тогда, принимая во внимание представленные выше характеристики форм человеческого капитала региона, определим основные индикаторы их оценки (таблица 1). 
Индикаторы оценки основных форм человеческого капитала региона Indicators for assessing the main forms of human capital in the region

\begin{tabular}{|c|c|c|}
\hline Форма капитала & Составляющие & Наименование индикаторов оценки \\
\hline \multirow[t]{3}{*}{ Физическая } & $\begin{array}{c}\text { Биофизический } \\
\text { человеческий капитал }\end{array}$ & $\begin{array}{l}\text { 1. Заболеваемость (уровень) на } 1000 \text { чел. } \\
\text { 2. Численность лиц, признанных инвалидами. } \\
\text { 3. Средняя продолжительность жизни населения. }\end{array}$ \\
\hline & $\begin{array}{c}\text { Демографический } \\
\text { капитал }\end{array}$ & $\begin{array}{l}\text { 1. Коэффициент естественного прироста населения. } \\
\text { 2. Численность населения трудоспособного возраста. } \\
\text { 3. Коэффициент миграционного прироста населения } \\
\text { на } 10000 \text { человек. }\end{array}$ \\
\hline & Здравоохранение & $\begin{array}{l}\text { 1. Обеспеченность врачами на } 10000 \text { населения. } \\
\text { 2. Инвестиции в здравоохранение. }\end{array}$ \\
\hline \multirow[t]{2}{*}{ Интеллектуальная } & Образование & 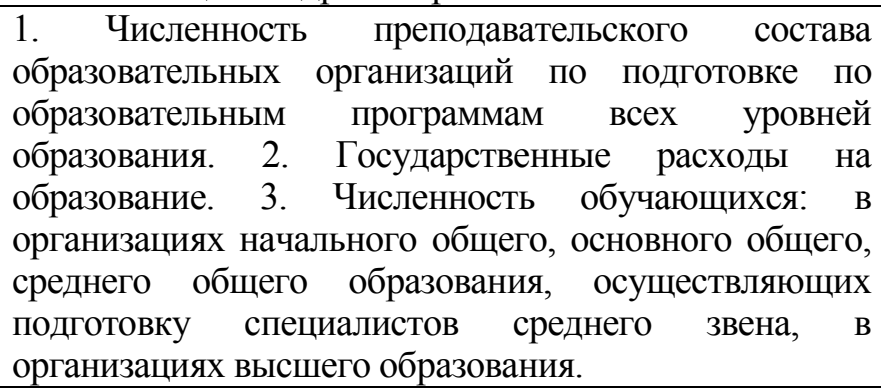 \\
\hline & $\begin{array}{c}\text { Научная и } \\
\text { инновационная } \\
\text { деятельность }\end{array}$ & $\begin{array}{l}\text { 1. Доля затрат на научно-исследовательские } \\
\text { разработки. 2. Число исследователей на } 1000 \text { человек } \\
\text { занятых в экономике. }\end{array}$ \\
\hline \multirow[t]{5}{*}{ Организационная } & $\begin{array}{l}\text { Анализ использования } \\
\text { трудового потенциала } \\
\text { региона }\end{array}$ & $\begin{array}{l}\text { 1. Удельный } \quad \text { вес } \quad \text { занятых } \quad \text { в } \text { структуре } \\
\text { трудоспособного населения. 2. Выбытие работников. } \\
\text { 3. Уровень безработицы. }\end{array}$ \\
\hline & $\begin{array}{l}\text { Профессиональный } \\
\text { уровень персонала }\end{array}$ & $\begin{array}{l}\text { 1. Уровень цифровых компетенций занятых в } \\
\text { экономике. 2. Число работников, прошедших курсы } \\
\text { повышения квалификации. 3. Удельный вес занятого } \\
\text { населения с высшим и средним профессиональным } \\
\text { образованием в составе занятого населения. }\end{array}$ \\
\hline & $\begin{array}{c}\text { Информационно- } \\
\text { компьютерные } \\
\text { технологии (ИКТ) на } \\
\text { предприятии } \\
\end{array}$ & $\begin{array}{l}\text { 1. Число персональных компьютеров на } 100 \text { занятых. } \\
\text { 2. Число компьютеров, имеющих выход в Интернет } \\
\text { на } 100 \text { занятых. 3. Доля организаций, имеющих } \\
\text { выделенные каналы. }\end{array}$ \\
\hline & $\begin{array}{c}\text { Производство } \\
\text { инновационной } \\
\text { продукции }\end{array}$ & $\begin{array}{l}\text { 1. Удельный вес инновационных товаров, работ, } \\
\text { услуг. } \\
\text { 2. Динамика разработанных передовых технологий. } \\
\text { 3. Уровень инновационной активности организаций. }\end{array}$ \\
\hline & Неофит форм бизнеса & $\begin{array}{l}\text { 1. Объемы рынка Интернет-торговли. 2. Доля } \\
\text { предприятий, имеющих веб-сайты. 3. Численность } \\
\text { фрилансеров. }\end{array}$ \\
\hline \multirow[t]{3}{*}{ Социальная } & $\begin{array}{l}\text { Уровень денежных } \\
\text { доходов населения }\end{array}$ & $\begin{array}{l}\text { 1. Доля населения с доходами ниже прожиточного } \\
\text { минимума. 2. Доходы населения по отношению к } \\
\text { прожиточному минимуму. 3. Коэффициент Джини. }\end{array}$ \\
\hline & $\begin{array}{c}\text { Денежные расходы } \\
\text { населения }\end{array}$ & $\begin{array}{l}\text { 1. Покупательная способность денежных доходов } \\
\text { населения. 2. Доля расходов на питание. 3. Величина } \\
\text { условно-свободной части располагаемого дохода. }\end{array}$ \\
\hline & $\begin{array}{l}\text { Уровень общественной } \\
\text { безопасности населения }\end{array}$ & $\begin{array}{l}\text { 1. Зарегистрированные преступления в расчете на } 100 \\
\text { тыс. чел. населения. 2. Обеспеченность населения } \\
\text { жильем. 3. Количество граждан, использующих } \\
\text { электронные площадки для получения государ- } \\
\text { ственных и муниципальных услуг. }\end{array}$ \\
\hline
\end{tabular}


Окончание табл. 1

\begin{tabular}{|c|c|c|}
\hline Форма капитала & Составляющие & Наименование индикаторов оценки \\
\hline \multirow[t]{3}{*}{ Сетевая } & $\begin{array}{l}\text { Уровень технико- } \\
\text { технологической } \\
\text { обеспеченности } \\
\text { населения }\end{array}$ & $\begin{array}{l}\text { 1. Число подключенных абонентских устройств } \\
\text { мобильной связи на } 1000 \text { человек населения. } \\
\text { 2. Число активных абонентов фиксированного } \\
\text { широкополосного доступа к сети Интернет. }\end{array}$ \\
\hline & $\begin{array}{c}\text { Формирование } \\
\text { цифровых компетенций }\end{array}$ & $\begin{array}{l}\text { 1. Доля населения с ИКТ навыками. 2. Доля } \\
\text { населения, } \quad \text { являющегося } \\
\text { пользователями сети Интернет. 3. Доля населения, } \\
\text { использующего интернет для заказа товаров и (или) } \\
\text { услуг, в общей численности населения. }\end{array}$ \\
\hline & $\begin{array}{c}\text { Цифровые } \\
\text { трансформации } \\
\text { коммуникационных } \\
\text { процессов }\end{array}$ & 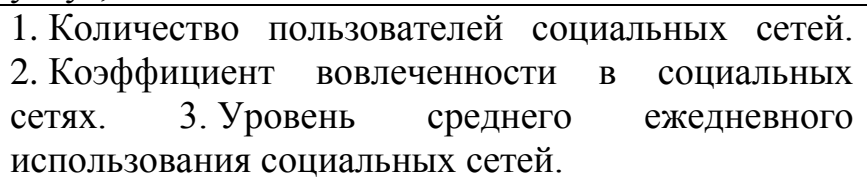 \\
\hline
\end{tabular}

Так, динамика основных показателей, характеризующих уровень техникотехнологической обеспеченности населения по двум основным показателям - числу подключенных абонентских устройств мобильной связи на 1000 человек населения развития сетевой формы человеческого капитала и числу активных абонентов, фиксированному в Центрально-черноземном регионе - приведена в таблице 2 и на рисунках 3, 4.

Таблица 2

Table 2

Динамика основных показателей, характеризующих уровень технико-технологической обеспеченности населения в Центрально-черноземном регионе

Dynamics of the main indicators characterizing the level of technical and technological provision of the population in the Central Black Earth Region

\begin{tabular}{|c|c|c|c|c|c|}
\hline \multirow{2}{*}{ Показатель/регион } & \multicolumn{5}{|c|}{ Годы } \\
\hline & 2014 г. & 2015 г. & 2016 г. & 2017 г. & 2018 г. \\
\hline \multicolumn{6}{|c|}{ Число подключенных абонентских устройств мобильной связи на 1000 человек населения } \\
\hline Белгородская область & 1788,8 & 1803,6 & 1819,0 & 1844,2 & 1833,4 \\
\hline Воронежская область & 1725,0 & 1790,3 & 1745,0 & 1794,8 & 1810,8 \\
\hline Курская область & 1752,8 & 1777,9 & 1808,9 & 1846,9 & 1823,8 \\
\hline Липецкая область & 1683,3 & 1693,9 & 1671,7 & 1790,1 & 1793,8 \\
\hline Тамбовская область & 1694,2 & 1776,2 & 1675,4 & 1714,0 & 1696,9 \\
\hline \multicolumn{6}{|c|}{$\begin{array}{c}\text { Число активных абонентов фиксированного широкополосного доступа к сети Интернет } \\
\text { на } 100 \text { человек населения }\end{array}$} \\
\hline Белгородская область & 13 & 17,6 & 18,6 & 19,2 & 19,4 \\
\hline Воронежская область & 18,4 & 19,9 & 20,1 & 23,9 & 24,7 \\
\hline Курская область & 14,9 & 22,5 & 24 & 28,3 & 22,9 \\
\hline Липецкая область & 12,8 & 14,9 & 16,1 & 18,1 & 22,5 \\
\hline Тамбовская область & 15,4 & 15,7 & 15,4 & 18,5 & 18,6 \\
\hline
\end{tabular}

Можно сделать вывод, что с точки зрения уровня технико-технологической обеспеченности населения наиболее благоприятная ситуация наблюдается в Курской и Воронежской областях. Тамбовская область значительно отстает по данной группе показателей, значит учет данного фактора, достаточно значимого в условиях цифровой трансформации, должен быть приоритетным в региональной политике данной области. 


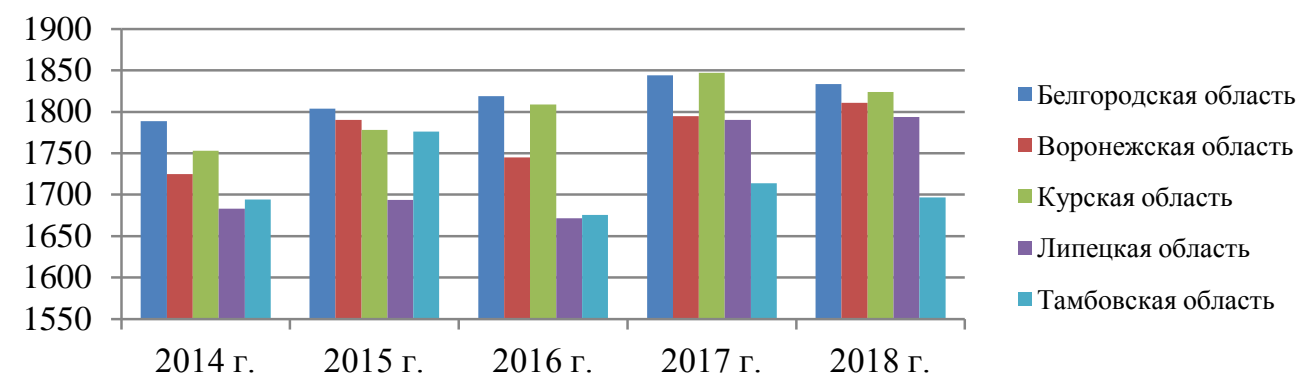

Рис. 3. Графическая интерпретация динамики основных показателей, характеризующих уровень технико-технологической обеспеченности населения в Центрально-черноземном регионе (число

подключенных абонентских устройств мобильной связи на 1000 человек населения)

Fig. 3. Graphical interpretation of the dynamics of the main indicators characterizing the level of technical and technological provision of the population in the Central Black Earth Region technological provision of the population in the Central Black Earth Region (number of connected mobile subscriber devices per 1000 population)

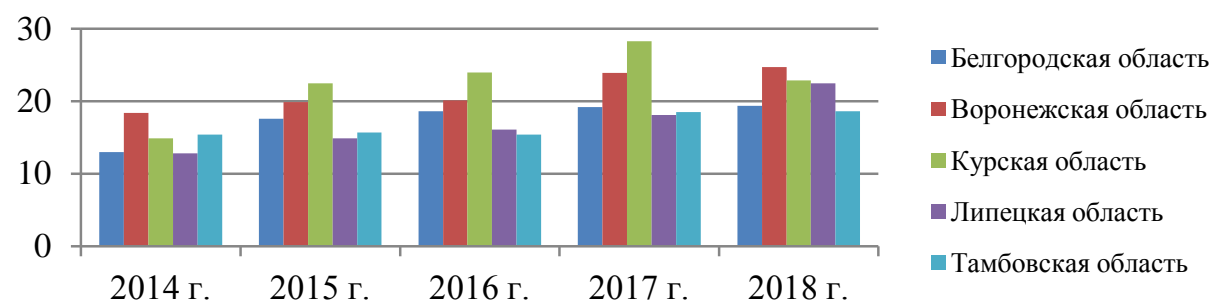

Рис. 4. Графическая интерпретация динамики основных показателей, характеризующих уровень технико-технологической обеспеченности населения в Центрально-черноземном регионе (число активных абонентов фиксированного широкополосного доступа к сети Интернет на 100 человек населения)

Fig. 4. Graphical interpretation of the dynamics of the main indicators characterizing the level of technical and technological provision of the population in the Central Black Earth Region technological provision of the population in the Central Black Earth Region (number of active subscribers of fixed broadband Internet access per 100 population)

\section{Заключение}

Резюмируя вышеизложенное, можно сделать следующие выводы:

- в условиях цифровой трансформации возникает новая форма человеческого капитала - сетевая, которая выдвигает новые требования и приводит к формированию новых компетенций человеческого капитала региона.

- построение системы агрегированных индикаторов человеческого капитала осуществляется на основании видовой диверсификации человеческого капитала - форм, подверженных изменениям, возникших в процессе влияния цифровых трансформаций на общество, а также их основных обособленных элементов, уровней и стадий воспроизводства, характеризующих данное видовое разнообразие с различных сторон рассмотрения;

- важной особенностью анализа индикаторов форм человеческого капитала является их согласованность, при этом наиболее полное представление о состоянии человеческого капитала может дать рассмотрение консолидации значений.

\section{Список литературы}

1. Васильева Е. 2010. Анализ методологических подходов к измерению человеческого капитала. Федерализм. 1: 89-96.

2. Добрынин А.И., Дятлов С.А., Цыренова Е.Д. 1999. Человеческий капитал в транзитивной экономике: формирование, оценка, эффективность использования. СПб.: Наука. 48-56. 
3. Доклад о развитии человека 2010. Реальное богатство народов: пути к развитию человека. ПРООН. Москва: Издательство «Весь Мир». 244 с.

4. Казмалова О.Н. 2012. Влияние человеческого капитала на валовой региональный продукт. Вестник Академии. 4: 100-107.

5. Кедрик Дж. Совокупный капитал США и его формирование. 1978. Москва: Прогресс. 63.

6. Кирьянов Д.А., Сухарева Т.Н. 2011. Методы оценки человеческого капитала: анализ объективности и достаточности исходных данных. Теория и практика общественного развития. 3: 337-340.

7. Лосева О.В. 2010. Автоматизированная информационная система для оценки регионального человеческого капитала. Известия Пензенского государственного педагогического университета им. В.Г. Белинского. 22: 163-173.

8. Макконелл В.И., Брю С.Л. 1992. Экономика: принципы, проблемы, политика. Москва: Республика. $171 \mathrm{c.}$

9. Минеева Н.Н., Неганова В.П. 2009. Характеристика видов человеческого капитала. Известия Уральского государственного экономического университета. 4 (26): 29-35.

10. Мызин А.Л., Гурбан И.А. 2011. Проблемы оценки человеческого капитала в контексте исследования национального богатства регионов России. Экономика региона. 1: 104-109.

11. Подберезкин А.И., Гебеков М.П. 2011. Россия: человеческий капитал и развитие человека в региональном измерении. Вестник МГИМО Университета. Т. 3. 3: 38-44.

12. Руденко Д.Ю. 2012. Развитие человеческого потенциала в Тюменской области. Академический вестник. 3: 43-48.

13. Соболева И.В. 2009. Парадоксы измерения человеческого капитала. Научный доклад. Москва: Институт экономики РАН. 50 с.

14. Спиридонова Е.М. 2010. Индекс развития человеческого потенциала как интегральный показатель уровня жизни населения регионов. Вестник СамГУПС. 4: 45-51.

15. Шафран А.М. 2011. Человеческий капитал как фактор инвестиционной привлекательности регионов России. Вестник Чувашского государственного педагогического университета им. И.Я. Яковлева. 3-1: 224-231.

16. Heckman J. J., Kautz T. 2012. Hard evidence on soft skills. Labour economics. 4: 451-464.

17. Voogt J. 2013. Challenges to learning and schooling in the digital networked world of the 21st century. Journal of computer assisted learning. T. 29. 5: 403-413.

18. Tapscott D. 2016. Blockchain Revolution: How the Technology Behind Bitcoin Is Canding Money, Bisiness. EndtheWorld. London: Penguin. 348 p.

19. Schulz T.W. 1971. Investment in Human Capital: The Role of Education and of Rearch. FreePress. 1: 64-65.

\section{References}

1. Vasileva E. 2010. Analysis of methodological approaches to measuring human capital. Federalism. 1: 89-96.

2. Dobrynin A. I., Dyatlov S. A., Tsyrenova E. D. 1999. Human capital in a transitive economy: formation, evaluation, and efficiency of use. SPb.: Nauka. 48-56.

3. human development Report 2010. Real wealth of Nations: ways to human development. UNDP. Moscow: Publishing House "Whole World". 244 p.

4. Kamalova O. N. 2012. The impact of human capital on the gross regional product. Bulletin Of The Academy. 4: 100-107.

5. Kedrick J. The aggregate capital of the US and its formation. 1978. Moscow: Progress. 63;

6. Kiryanov D. A., Sukhareva T. N. 2011. Methods of evaluating human capital: an analysis of the objectivity and adequacy of the source data. Theory and practice of social development. 3: 337-340.

7. Loseva O. V. 2010. Automated information system for assessing regional human capital. Izvestiya Penza state pedagogical University named after V. G. Belinsky. 22: 163-173. $171 \mathrm{PP}$.

8. McConnell V. I., BRU S. L. 1992. Economics: principles, problems, politics. Moscow: Republic.

9. Mineeva N. N., Neganova V. P. 2009. Characteristics of types of human capital. Izvestiya Uralskogo gosudarstvennogo ekonomicheskogo universiteta. 4 (26): 29-35.

10. Myzin A. L., Gurban I. A. 2011. Problems of human capital assessment in the context of the study of the national wealth of Russian regions. Regional economy. 1: 104-109. 
11. Podberezkin A. I., Gebekov M. P. 2011. Russia: human capital and human development in the regional dimension. Bulletin of MGIMO University, Vol. 3. 3: 38-44.

12. Rudenko D. Yu. 2012. Human development in the Tyumen region. Academic Bulletin. 3: 43-48.

13. Soboleva I. V. 2009. Paradoxes of measuring human capital. Scientific report. Moscow: Institute of Economics, Russian Academy of Sciences, 50 p.

14. Spiridonova, E. M. 2010. Human development index as an integral indicator of the standard of living of the population of the regions. Bulletin Of The Samara State. 4: 45-51.

15. Shafran A.m. 2011. Human capital as a factor of investment attractiveness of Russian regions. Bulletin of the Chuvash state pedagogical University named after I. Ya. Yakovlev. 3-1: 224-231.

16. Heckman J. J., Kautz T. 2012. Hard evidence on soft skills. Labour economics. 4: 451-464.

17. Voogt J. 2013. Challenges to learning and schooling in the digital networked world of the 21st century. Journal of computer assisted learning. T. 29. 5: 403-413.

18. Tapscott D. 2016. Blockchain Revolution: How the Technology Behind Bitcoin Is Canding Money, Bisiness. EndtheWorld. London: Penguin. 348 p.

19. Schulz T.W. 1971. Investment in Human Capital: The Role of Education and of Rearch. FreePress. 1: 64-65.

\section{ИНФОРМАЦИЯ ОБ АВТОРАХ}

Стрябкова Елена Анатольевна, доктор экономических наук, доцент, заведующая кафедрой прикладной экономики и экономической безопасности Белгородского государственного национального исследовательского университета, Белгород, Россия

Вейс Елена Владимировна, ассистент кафедры бухгалтерского учета и налогового контроля Тамбовского государственного университета им. Г.Р. Державина, Тамбов, Россия

\section{INFORMATION ABOUT THE AUTHORS}

Elena A. Stryabkova, Doctor of Economic Sciences, Associate professor, Head of the Department of Applied Economics and Economic Security Belgorod National Research University, Belgorod, Russia

Elena V. Weis, Assistant of the Department of Accounting and Tax Control Tambov State University named after G.R. Derzhavin, Tambov, Russia 